\title{
Rancang Bangun Sistem Monitoring Kualitas Air (pH dan Kekeruhan) pada Akuarium Berbasis Internet of Things
}

\author{
Haryanto $^{* 1}$, Kristono ${ }^{2}$, Muhammad Fadhil ${ }^{3}$ \\ 1,3Program Studi Sistem Komputer, STMIK AUB, Surakarta, Indonesia \\ ${ }^{2}$ Program Studi Sistem Informasi, STMIK AUB, Surakarta, Indonesia \\ e-mail: *1haryanto@stmik-aub.ac.id, ${ }^{2 k}$ kristono@stmik-aub.ac.id, \\ 33azzafadhil10@gmail.com
}

\begin{abstract}
Abstrak
Ketertarikan masyarakat terhadap pemeliharaan ikan-ikan hias di era modernisasi ini semakin meningkat. Untuk tetap menjaga kualitas habitat ikan diakuarium, maka dibutuhkanlah perawatan agar ikan-ikan tersebut tidak mati atau terpelihara dengan baik. Perawatan digunakan untuk menjaga kelangsungan hidup ikan dan vegetasi air yang terdapat didalamnya termasuk keasaman dan kekeruhan sangat menentukan kualitas air karena juga sangat menentukan proses kimiawi dalam air. Dalam perkembangan teknologi yang semakin canggih contohnya seperti Internet of Things (IoT), IoT ini dapat memberikan manfaat dalam keperluan untuk monitoring dan kontrol pada akuarium. Maka tujuan penelitian ini untuk mengembangkan dan membuat alat sistem monitoring kualitas air dengan sensor pH dan kekeruhan pada akuarium berbasis Internet of Things dengan metode research and development. Dari penelitian ini untuk menjawab dan mencoba dipecahkan dengan dibangunnya sistem monitoring kualitas air pada akuarium dengan mikrokontroler ATmega328P dengan sensor pH Module V.1.1, RED Turbidity sensor dan memanfaatkan aplikasi Blynk sebagai antarmuka monitoring pada smartphone. Hasil penelitian ini berupa mengembangkan alat sistem monitoring kualitas air ( $\mathrm{pH}$ dan kekeruhan) pada akuarium berbasi IoT dengan mikrokontroler ATmega328P yang berisikan perintah untuk mengatur $\mathrm{pH}$ dan kekeruhan air dengan sensor pH Module V.1.1 dan RED Turbidity Sensor pada akuarium. Kesimpulan dari penelitian yang dilakukan adalah dapat membantu monitoring secara jarak jauh yang update secara real-time dan penggunaan sensor $p H$, sensor kekeruhan untuk menentukan batas kualitas air sesuai dengan yang dibutuhkan.
\end{abstract}

Kata kunci-Sistem, Monitoring, Mikrokontroler, Arduino, pH (power of hydrogen)

\begin{abstract}
Public interest in the maintenance of ornamental fish in this modernization era is increasing. To maintain the quality of fish habitat in the aquarium, care is needed so that the fish do not die or are well cared for. Treatment is used to maintain the survival of fish and aquatic vegetation contained therein, including acidity and turbidity which greatly determines water quality because it also greatly determines the chemical processes in water. In the development of increasingly sophisticated technologies such as the Internet of Things (IoT), IoT can provide benefits in the need for monitoring and control in aquariums. So a research was conducted on how to develop and make a water quality monitoring tool with a $\mathrm{pH}$ and turbidity sensor in aquarium based Internet of Things using methods research and development. From this research to answer and try to solve it by building a water quality monitoring system in an aquarium with an ATmega328P microcontroller with $\mathrm{pH}$ Module V.1.1 sensor, RED Turbidity sensor and utilizing the Blynk application as a monitoring interface on a smartphone. The result of this research is to develop a water quality monitoring tool with the ATmega328P
\end{abstract}


microcontroller which contain commands to adjust $\mathrm{pH}$ and water turbidity with the $\mathrm{pH}$ Module V.1.1 sensor and RED Turbidity sensor in the aquarium. The conclusion of the research conducted is that it can help remote monitoring which updates in real-time and the use of $\mathrm{pH}$ sensors, turbidity sensors to determine water quality limits as needed.

Keywords - System, Monitoring, Microcontroller, Arduino, $p H$ (power of hydrogen)

\section{PENDAHULUAN}

Internet of Things mendeskripsikan jaringan objek fisik yaitu "benda" yang tertanam dengan sensor, perangkat lunak, dan teknologi lain untuk tujuan menghubungkan dan bertukar data dengan perangkat dan sistem lain melalui internet. IoT ini sudah berkembang pesat mulai dari konvergensi teknologi nirkabel, micro-electromechanical systems (MEMS), dan juga internet. Sederhananya istilah Internet of Things ini mengacu pada mesin atau alat yang bisa diidentifikasikan sebagai representasi virtual dalam strukturnya yang berbasis internet [3].

Teknologi Internet of Things (IoT) bisa memberikan manfaat dalam keperluaan monitoring dan kontrol terhadap parameter lingkungan contohnya seperti akuarium. Sistem pemantau dan mengontrol akuarium dalam pemeliharaan ikan hias dari jarak jauh dapat dimanfaatkan oleh pemilik ikan hias. Proses pemeliharaan ikan hias yang baik akan membuat ikan hias tersebut sehat, dikarenakan kondisi air dan pakan ikan mempengaruhi kesehatan ikan tersebut [4].

Sejauh ini ketertarikan masyarakat terhadap ikan-ikan hias semakin meningkat, keragaman spesies ikan hias di Indonesia paling banyak di dunia dan sentra lokal ikan hias juga sangat berkembang pesat. Akuarium ikan dirumah tidak hanya menambah keindahan dari setiap sudut rumah, tetapi juga diyakini akan menguntungkan. Akuarium membutuhkan perawatan untuk menjaga kelangsungan hidup ikan dan vegetasi air yang terdapat didalamnya. Selain rutinitas pemberian pakan, nilai parameter lingkungan akuarium juga perlu senantiasa diawasi dan dijaga pada rentang tertentu. $\mathrm{pH}$ dan kekeruhan sangat menentukan kualitas air karena juga sangat menentukan proses kimiawi dalam air. Hubungan keasaman air dengan kehidupan ikan sangat besar. Titik kematian ikan pada $p H$ asam adalah 4 dan pada $p H$ basa adalah 11[1]. Serta tingkat kejernihan air yang disarankan berdasarkan standar kekeruhan air yaitu 5-25 NTU [2].

Dalam proses perawatan akuarium objek penelitian saudara Naufal Maarif yang berada di Cemani, perawatan yang biasanya dilakukan adalah dengan menjaga rutinitas pemberian pakan agar tidak berlebihan dan penggantian air akuarium secara berkala. Akan tetapi, dalam proses me-monitoring kualitas air akuarium itu belum terotomatisasi. Dan keadaan kualitas air dalam akuarium tersebut tidak bisa di cek kadar $p H$ di air dan tingkat kekeruhannya masih dalam batas yang normal atau tidak. Permasalahan tersebut dapat terjadi, bisa mengakibatkan kerusakan parameter ekosistem lingkungan akuarium dan juga menyebabkan beberapa ikan yang mati karena tidak cocok dengan habitat kualitas air. Oleh karena itu, dalam pemeliharaan ikan sebaiknya kondisi air dijaga dan dari kendala tersebut solusi untuk me-monitoring kualitas air bisa dengan memanfaatkan teknologi Internet of Things (IoT) pada smartphone yang bisa digunakan dari jarak jauh maupun dekat dan sudah terotomatisasi dengan ketentuan kualitas air yang sudah dibuat.

Akhirnya dari pendahuluan tersebut dipecahkan permasalahanya dan dilaporkan menjadi penelitian untuk program S1-Sistem Komputer STMIK Adi Unggul Bhirawa (AUB) berjudul "Rancang Bangun Sistem Monitoring Kualitas Air ( $\mathrm{pH}$ dan Kekeruhan) Pada Akuarium Berbasis Internet Of Things". 


\section{METODE PENELITIAN}

\subsection{Unit Penelitian}

Penelitian dilaksanakan dengan narasumber yang bertempat di Jalan Cemani, Kecamatan Grogol, Kabupaten Sukoharjo, Kota Surakarta, Jawa Tengah. Penelitian dilakukan dengan me-monitoring kualitas air pada akuarium narasumber dengan sensor $p H$ dan sensor kekeruhan secara real-time dengan berbasis internet.

\subsection{Teknik Pengumpulan Data}

Metode pengumpulan data adalah teknik atau cara yang dilakukan oleh peneliti untuk mengumpulkan data. Metode pengumpulan data yang digunakan penulis antara lain:

a. Wawancara

Merupakan metode pengumpulan data yang dilakukan melalui tatap muka dan tanya jawab langsung antara peneliti dan narasumber dengan yang bersangkutan saudara Naufal Maarif dengan durasi wawancara sebanyak 1 kali pertemuan, akan memberikan informasi tentang keadaan kondisi kualitas air ( $\mathrm{pH}$ dan kekeruhan) aquascape yang dibutuhkan dalam penelitian.

b. Pengamatan

Pengumpulan data yang dilakukan dengan sengaja, sistematis mengenai fenomena sosial dan gejala fisis untuk kemudian dilakukannya pencatatan. Dalam kaitannya dengan penelitian ini, penelitian langsung terjun ke lokasi saudara Naufal Maarif dan menjadi partisipan (observer partisipatif) untuk menemukan dan mendapatkan hasil pengamatan yang berkaitan dengan fokus penelitian.

c. Dokumentasi

Yaitu dengan mengumpulkan hasil dokumentasi dari pengamatan yang terkait dengan fokus penelitian yang berasal dari sumber utamanya (objek penelitian) yaitu kualitas air ( $\mathrm{pH}$ dan kekeruhan) pada aquascape saudara Naufal Maarif.

\subsection{Tahap-Tahap Penelitian}

Pada tahap penelitian ini, penelitian mengacu model pengembangan (research and development) [5] seperti pada Gambar 1.

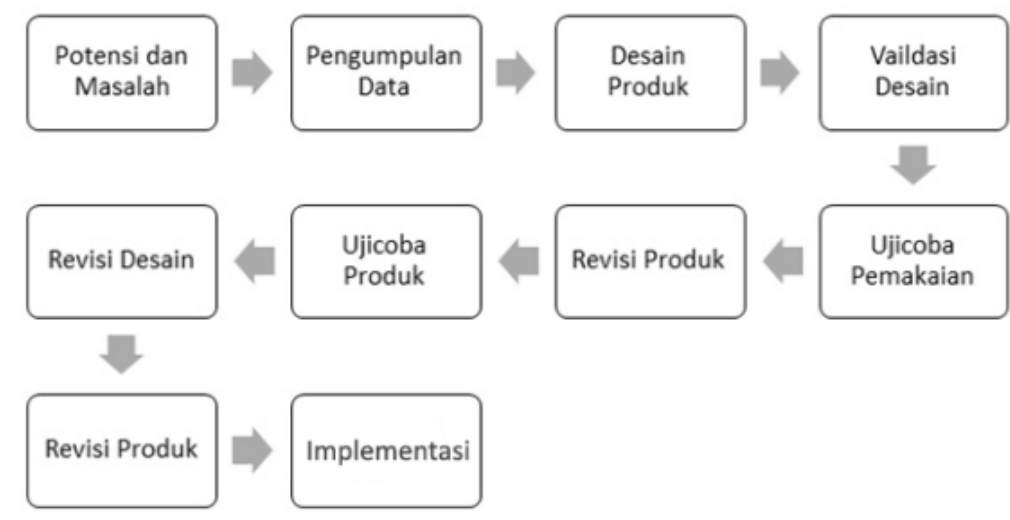

Gambar 1. Metode Penelitian Research and Development

Penelitian ini mengambil tujuh langkah dalam proses Gambar 1. Hal ini dilakukan karena penelitian pengembangan yang dilakukan hanya untuk perorangan saja dan menyusaikan pada 
karakteristik, keterbatasan waktu, tenaga dan biaya. Adapun langkah-langkah yang diambil sebagai berikut :

a. Analisis kebutuhan dengan melakukan pengamatan dan pengumpulan informasi dengan saudara Naufal Maarif mengenai keadaan akuarium atau aquascape narasumber. Analisis kebutuhan data ini sendiri yang butuhkan dalam penelitian mengenai data kualiatas air yatiu, data $p H$ dan data dari kekeruhan air tersebut.

b. Melakukan perencanaan perancangan pembuatan alat. Perencanaan perancangan ini mengambil sistem flowchart, blok diagram dan skematik rangkaian.

c. Mengembangkan bentuk awal perancangan alat, yang selajutnya dievaluasi lagi dan direvisi kembali. Ditahap ini, merupakan kegiatan penentuan desain produk / alat yang dikembangkan yaitu penentuan kebutuhan hardware dan software.

d. Melakukan pembuatan alat. Dalam pembuatan alat ini, peneliti menggunakan mikrokontroler ATmega328P dengan sensor $p H$ Module V.1.1 dan sensor kekeruhan RED Turbidity dan melakukan pemrograman pada Arduino IDE 1.8.5 dengan bahasa pemrograman $C$.

e. Melakukan pembuatan software. Tahap pembuatan software ini sendiri menggunakan Blynk App untuk antarmuka alat pada smartphone.

$f$. Melakukan uji coba alat yang dibuat.

g. Mengambil kesimpulan dari uji coba dan membuat rancangan akhir.

\subsection{Flowchart Sistem}

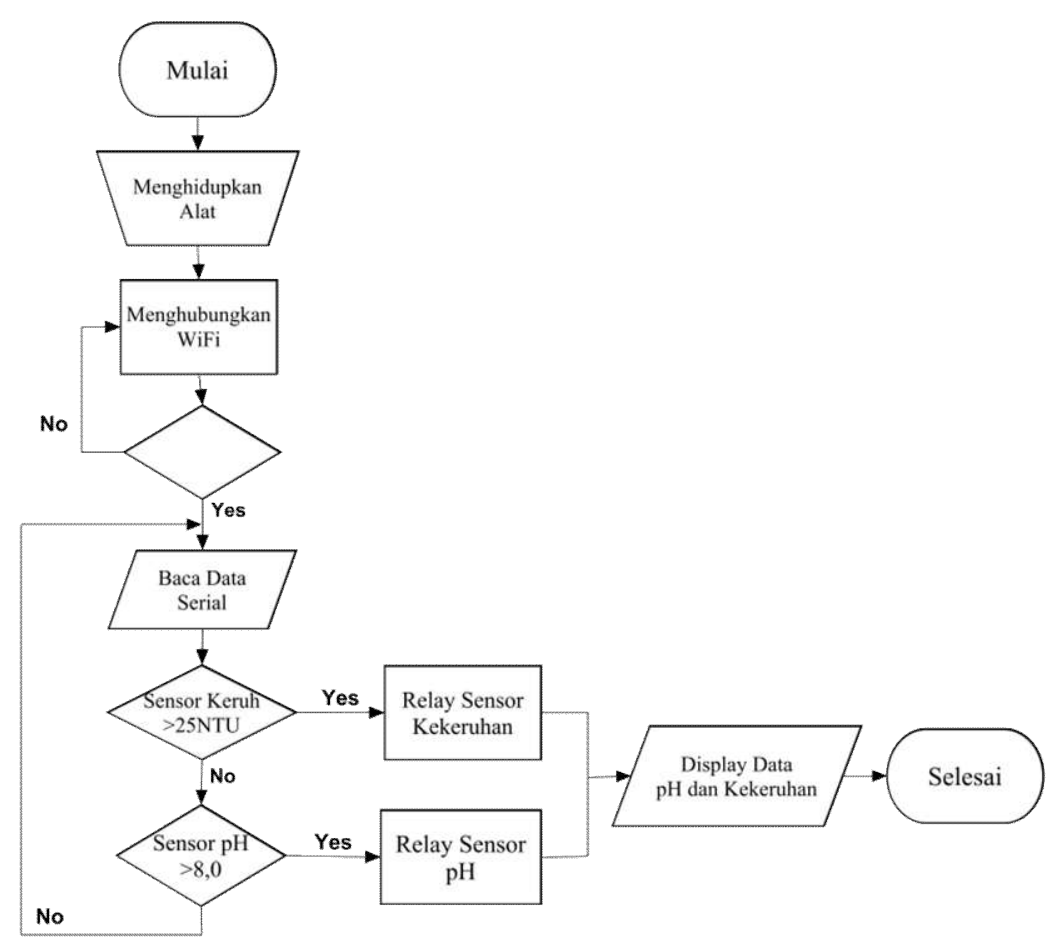

Gambar 2. Flowchart Sistem Monitoring Kualitas Air

\section{HASIL DAN PEMBAHASAN}

\subsection{Implementasi}

Langkah untuk membangun interface sistem monitoring menggunakan platfrom dari aplikasi android Blynk, yaitu :

a. Download dan Install aplikasi Blynk melalui "playstore".

b. Buka aplikasi Blynk dan sign up new account atau login jika sudah memiliki akun. Tampilan awal pada Blynk dapat dilihat pada Gambar 3. 


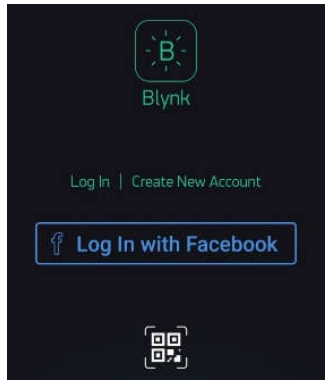

Gambar 3. Tampilan Awal pada Blynk

c. Buat new project, kemudian beri nama "Monitoring Aquascape" kemudian choose device pilih "Arduino Uno" connection type "WiFi" kemudian klik create. Langkah cara membuat new project dapat dilihat pada Gambar 4.

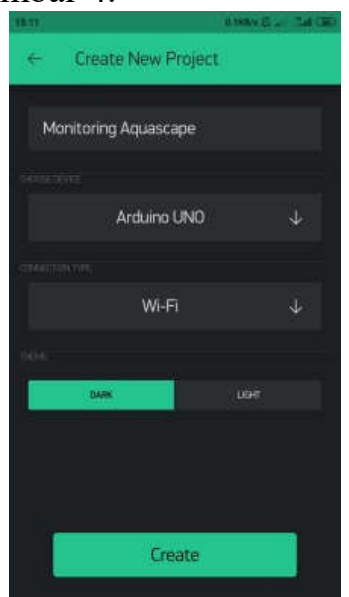

Gambar 4. Pembuatan New Project

d. Setelah membuat new project, kita mendapat auth token yang digunakan agar project yang ada pada Blynk dapat mengenali mikrokontroler yang digunakan untuk membangun sistem monitoring kualitas air. Auth token dikirim melalui email yang digunakan untuk sign up, tampilan dari auth token dapat dilihat pada Gambar 5.

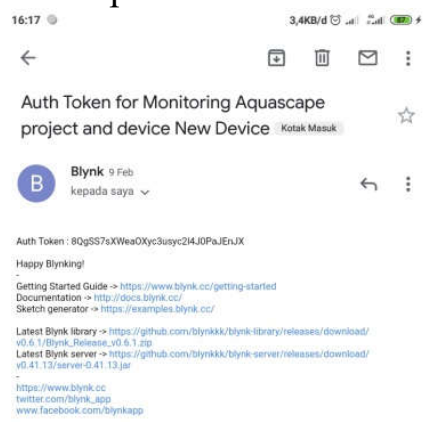

Gambar 5. Pesan Auth Token pada Gmail

e. Menambahkan widget display lcd untuk menampilkan monitoring data dari sensor kekeruhan dan adc kekeruhan, klik widget lcd lalu pada type input pilih advanced dan pada pin virtual pilih V0. Widget Display LCD sensor kekeruhan dan adc kekeruhan dapat dilihat pada Gambar 6. 


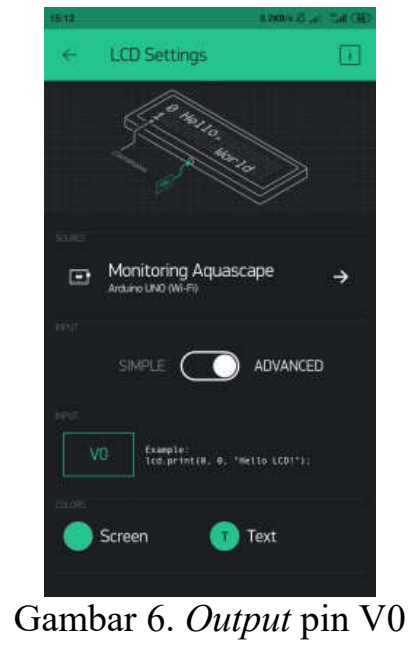

f. Lakukan juga menambahkan widget display lcd lagi untuk menampilkan monitoring data dari sensor $p H$ dan adc $p H$, klik widget lcd lalu pada type input pilih advanced dan pada pin virtual pilih V1. Widget Display LCD sensor $\mathrm{pH}$ dan adc $\mathrm{pH}$ dapat dilihat pada Gambar 7.

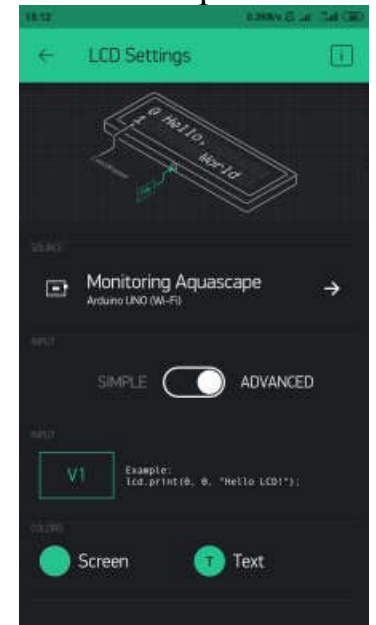

Gambar 7. Output pin V1

g. Setelah itu tambahkan widget SuperChart Sensor Keruh, Adc Keruh, Sensor $p H$ dan $A d c p H$ yang ditunjukkan pada Gambar 8.

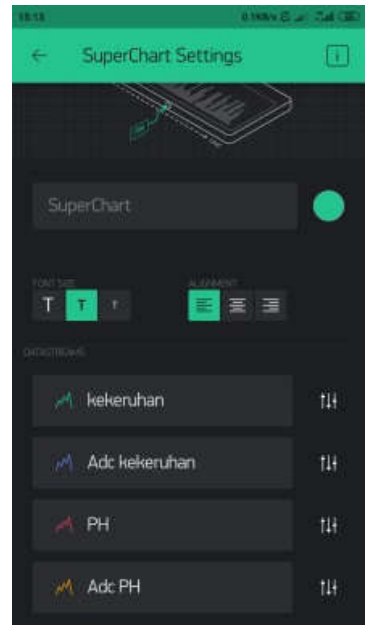

Gambar 8. Tampilan SuperChart

h. Kemudian tambahkan widget led untuk relay pada sensor kekeruhan, dan pada virtual pin pilih $V 6$ seperti pada Gambar 9. 


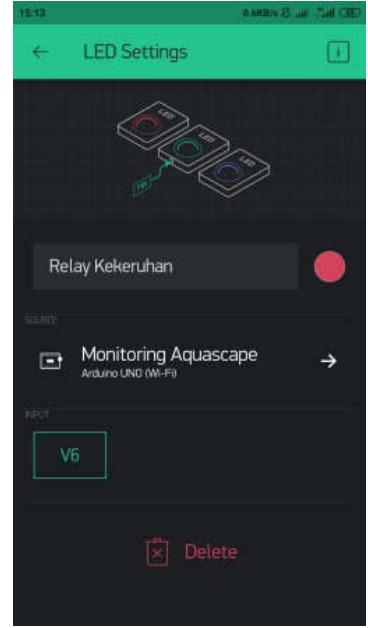

Gambar 9. Display Relay Sensor Kekeruhan

i. Ulangi langkah untuk membuat widget led pada relay $p H$, dan pada virtual pin pilih $V 7$ perintah seperti pada Gambar 10.

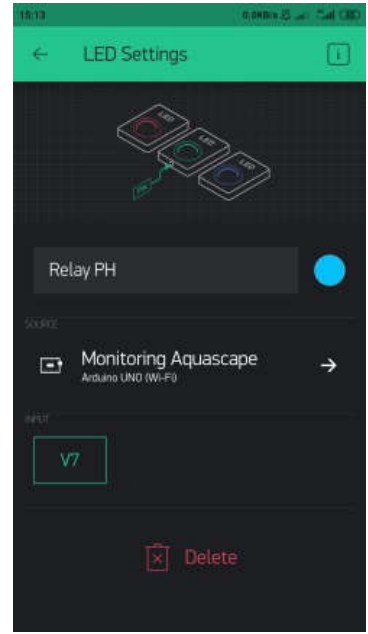

Gambar 10. Display Relay Sensor $p H$

j. Setelah semua setting-an telah dibuat maka interface pada aplikasi Blynk akan seperti pada Gambar 11.

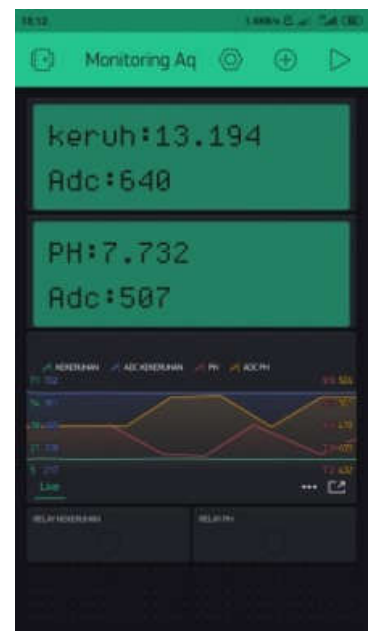

Gambar 11. Tampilan antarmuka Monitoring pada aplikasi Blynk 


\subsection{Pengujian Kendali Lampu}

Pengujian sistem monitoring kualitas air pada akuarium diperlukan untuk melihat apakah sistem yang dibangun telah bekerja dengan baik. Hasil dari pengujian adalah sebagai berikut :

a. Pengujian pada kualitas air yang bersih

Pada pengujian air bersih, hasil uji coba pada objek tingkat kekeruhan pada rentang 0,30 sampai dengan 1,39 NTU dan adc kekeruhan pada rentang 735 sampai 727 menghasilkan ouput pompa dalam keadaan off. Untuk objek tingkat $p H$ pada rentang 7,01 sampai dengan 7,79 dan adc $p H$ pada rentang 493 sampai 505 menghasilkan output pompa dalam keadaan off. Percobaan sistem monitoring pada air bersih dapat dilihat pada Gambar 12.

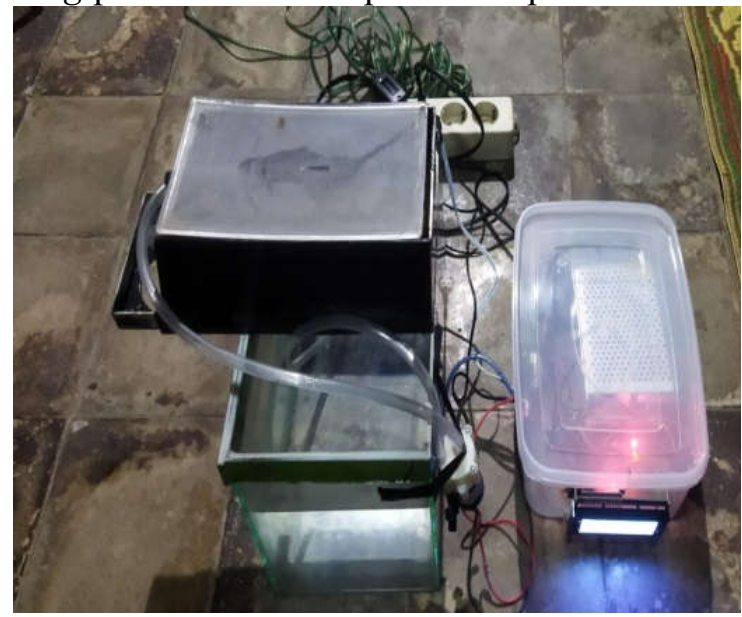

Gambar 12. Percobaan pada Air Bersih

b. Pengujian pada kualitas air yang keruh

Pada pengujian kualitas air keruh, hasil uji coba pada objek tingkat kekeruhan pada rentang 12,65 sampai dengan 18,87 NTU dan adc kekeruhan pada rentang 632 sampai 650 menghasilkan ouput pompa dalam keadaan off. Untuk objek tingkat $p H$ pada rentang 7,50 sampai dengan 7,93 dan adc pH pada rentang 501 sampai 515 menghasilkan output pompa dalam keadaan off. Percobaan sistem monitoring pada air keruh dapat dilihat pada Gambar 13 dan 14.

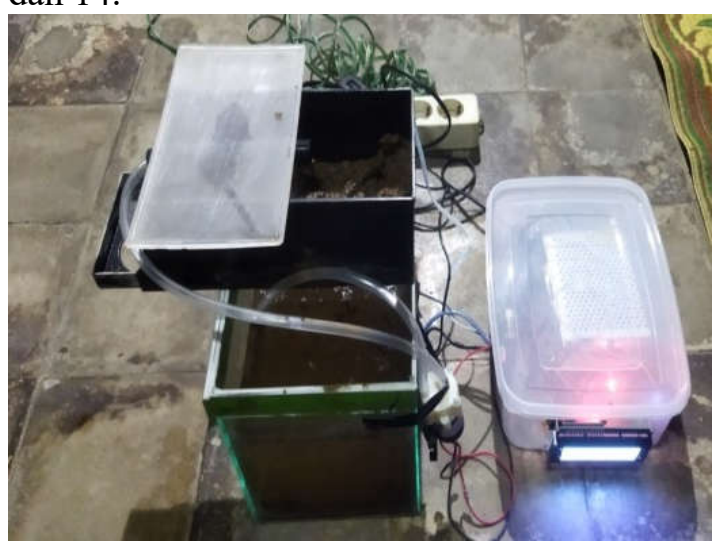

Gambar 13. Percobaan pada Air Keruh

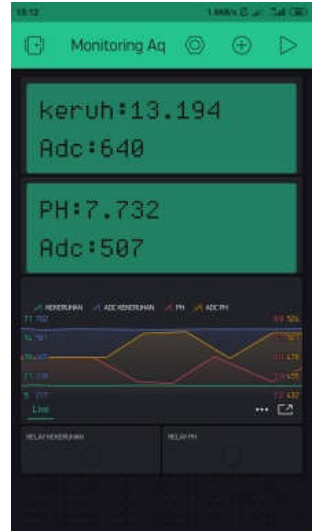

Gambar 14. Tampilan Hasil Percobaan pada Air Keruh

c. Pengujian pada kualitas air yang sangat keruh

Pada pengujian air yang sangat keruh, hasil uji coba pada objek tingkat kekeruhan pada rentang 26,62 sampai dengan 28,52 NTU dan adc kekeruhan pada rentang 523 sampai 548 menghasilkan ouput pompa dalam keadaan on. Untuk objek tingkat $p H$ pada rentang 7,13 sampai dengan 7,33 dan adc pH pada rentang 421 sampai 528 menghasilkan output pompa 
dalam keadaan off. Percobaan sistem monitoring pada air yang sangat keruh dapat dilihat pada Gambar 15 dan 16.

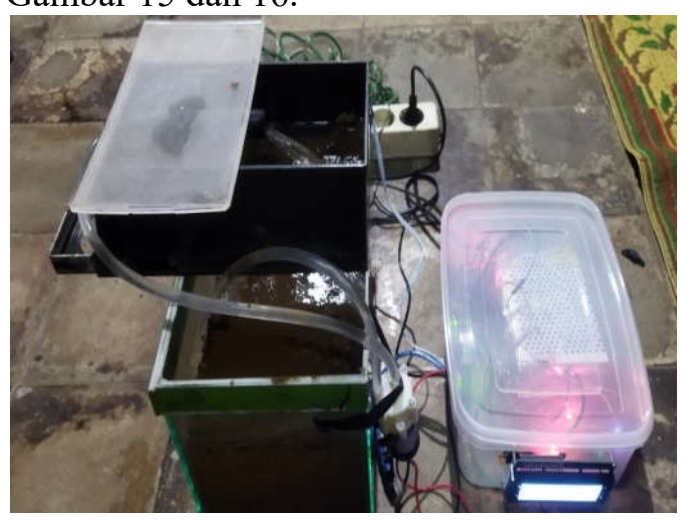

Gambar 15. Percobaan pada Air yang sangat Keruh

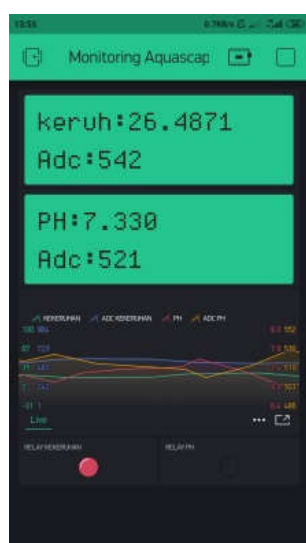

Gambar 16. Tampilan Hasil Percobaan Pada Air yang sangat Keruh

d. Pengujian pada kualitas air sabun/detergen yang mengandung asam basa

Pada pengujian air yang mengandung asam basa, hasil uji coba pada objek tingkat kekeruhan pada rentang 8,31 sampai dengan 9,40 NTU dan adc kekeruhan pada rentang 663 sampai 684 menghasilkan ouput pompa dalam keadaan off. Untuk objek tingkat $p H$ pada rentang 9,11 sampai dengan 9,60 dan adc $p H$ pada rentang 443 sampai 460 menghasilkan output pompa dalam keadaan on. Percobaan sistem monitoring pada air yang mengandung asam basa dapat dilihat pada Gambar 17 dan 18.

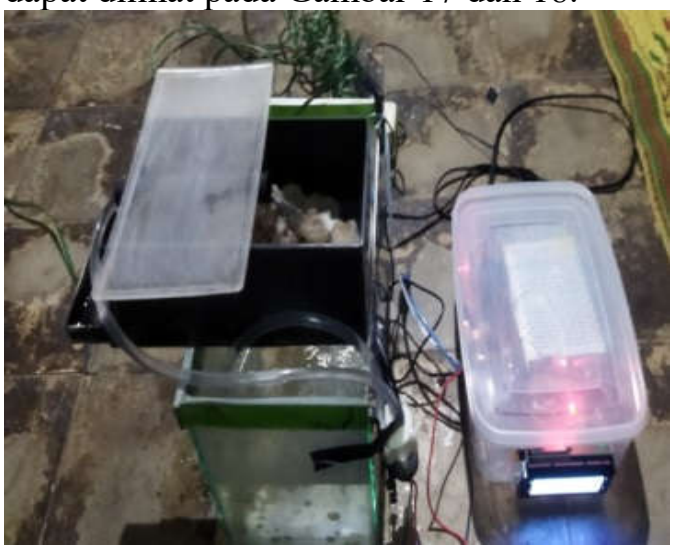

Gambar 17. Percobaan pada Air Asam Basa

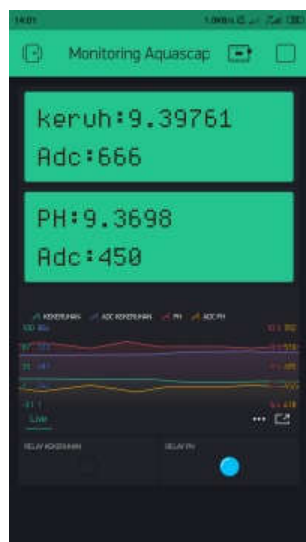

Gambar 18. Tampilan Percobaan pada Air Asam Basa

\subsection{Pembahasan}

a. Buka aplikasi Blynk, dan pilih tombol "RUN"

b. Interface kendali lampu dapat dilihat pada Gambar 19. 


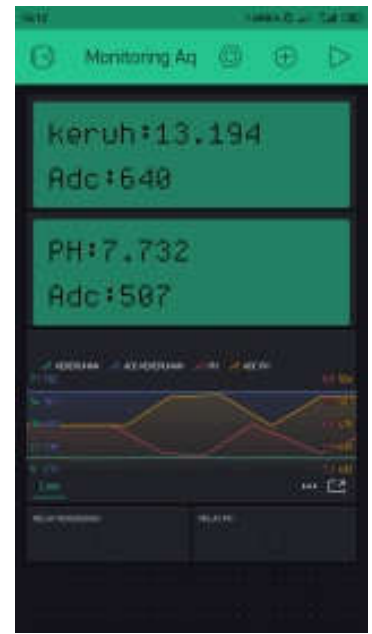

Gambar 19. Interface Sistem Monitoring Kualitas Air

Pada Gambar 19, Smartphone android yang sudah ter-install Bylnk akan menampilkan interface sistem monitoring kualitas air pada akurium dengan sensor $p H$ Module V.1.1 dan RED Turbidity Sensor. Setelah itu ketika sistem sensor $\mathrm{pH}$ membaca data kententuan $\mathrm{pH}$ air melebihi 8,5 maka secara otomatis relay $p H$ akan bekerja untuk menggerakkan pompa air, begitu juga sebaliknya ketika sistem sensor kekeruhan membaca data ketentuan kekeruhan air melebihi 25 NTU maka secara otomatis relay kekeruhan akan bekerja juga untuk menggerakan pompa air. Jika sistem sensor membaca data yang tidak melebihi ketentuan pada tiap sensornya maka akan tetap menampilkan data keadaan kualitas air akuarium yang update secara real-time pada aplikasi Blynk di smartphone android sebagai interface sistem monitoring kualitas air pada akuarium dan $L C D$ pada sistem.

\section{KESIMPULAN}

Berdasarkan dari penelitian dan uji coba alat monitoring kualitas air pada akuarium menggunakan metode penelitian research and development dan menggunakan flowchart sebagai metode untuk perancangan dengan menggunakan bahasa pemrograman $C$, maka dapat disimpulkan sebagai berikut sistem monitoring kualitas air dapat me-monitoring kualitas $p H$ dan kekeruhan air pada akuarium yang update secara real-time dari jarak jauh maupun dekat dengan teknologi IoT (Internet of Things) dan memanfaatkan Blynk sebagai antarmuka monitoring pada smartphone, Penggunaan sensor $p H$ Module V.1.1 pada alat monitoring kualitas air dapat menentukan kadar $p H$ pada air akuarium dan alat akan melakukan pompa secara otomatis dengan batas ketentuan $\mathrm{pH}$ air diatas 8,0 dan untuk penggunaan RED Turbidity Sensor dapat menentukan tingkat kekeruhan pada air akuarium dengan batas ketentuan 25NTU dan alat akan melakukan pompa secara otomatis jika melebihi dari batas ketentuan tingkat keruh.

\section{SARAN}

Dalam rancang bangun sistem masih terdapat kekurangan baik dari software, hardware maupun jaringan, oleh karena itu untuk pengembangan lebih lanjut penulis menyarankan penambahan sensor kelembapan untuk mengaktifkan dan menonaktifkan lampu secara otomatis pada akuarium dengan ketentuan kelembapan yang dibuat. Penambahan fitur water level untuk memastikan kondisi air pada akuarium sesuai dengan kebetuhan dan dapat mengisi akuarium jika kekurangan batas air. 


\section{DAFTAR PUSTAKA}

[1] Andria M., A. F., \& Rahmaningsih, S. (2018). Kajian Teknis Faktor Abiotik pada Embung Bekas Galian Tanah Liat PT.Semen Indonesia Tbk. untuk Pemanfaatan Budidaya Ikan dengan Teknologi KJA. Jurnal Ilmiah Perikanan dan Kelautan (JIPK) Vol.10, No.2, 99.

[2] Brahmantika, A., Ashari, M. I., \& Sotyohadi. (2019). Sistem Otomatisasi Budidaya Tumbuhan Aquascape Berbasis Arduino Uno. Seminar Nasional Elektro S1 ITN Malang, 1.

[3] Najib, W., Sulistyo, S., \& Widyawan. (2020). Tinjauan Ancaman dan Solusi Keamanan pada Teknologi Internet of Things. Jurnal Nasional Teknik Elektro dan Teknologi Informasi Vol.9, No.4, 375.

[4] Sukmadinata, N. S. (2007). Merode Penelitian dan Pendidikan. Bandung.

[5] Tadeus, D. Y., Azazi, K., \& Ariwibowo, D. (2019). Model Sistem Monitoring $p H$ dan Kekeruhan pada Akuarium Air Tawar Berbasis Internet of Things. Metana : Media Komunikasi Rekayasa Proses dan Teknologi Tepat Guna, 50. 